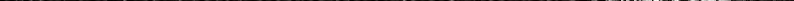


Compunell if 3 (i-1) 




\section{ON THE THEORY}

$\mathrm{OF}$

\section{THE ORIGIN OF SPECIES}

BY

\section{NATURAL SELECTION}

IN THE STRUGGLE FOR LIFE

JOHN CRAWFURD, ESQ. F.R.S

[PRIVATELY PRINTED]

\section{LONDON}

SPOTTISWOODE \& CO., PRINTERS, NEW-STREET SQUARE 



\section{ORIGIN OF SPECIES BY NATURAL SELECTION.}

I PRopose in this Paper tostate, in so far as concerns the natural history of Man, such objections to the Darwinian theory as have occurred to me, and which oblige me to refuse my belief in opinions which have received the assent of many eminent men of science. In doing so, I hope I shall be found to state them in those terms of respect and deference which are justly due to them and more especially to the ingenious, accomplished, and candid author of the theory.

The Darwinian theory was suggested by the well-known difficulty of determining in plants and animals what it is that constitutes a species when many species so closely resemble others as to seem but mere varieties. Hence it has been inferred that, in the course of countless ages, a small number of crude types, through a process of beneficial natural variations, have been transmuted into the many species into which the organic world is now divided. The object of the theory is to demonstrate that the whole organic creation did not, as geological evidence would seem to show, originate in a series of cataclysms, but, on the contrary, had its source in causes gradually and continuously in action, and differing in no respect from those at present in actual operation. This view supposes all organised beings to be derived from a few, or even from one progenitor or prototype. 'I cannot doubt,' says Mr. Darwin, 'that the theory of descent by gradation embraces all the members of the same class. I believe that animals have descended from 
at most only four or five progenitors, and plants from an equal or even lesser number.' He is, indeed, disposed to go further than this, and to derive all organised beings whatsoever from a single progenitor. Here, however, he judges from the analogous structures and chemical composition of all plants and animals, but admits that analogy may be an unsafe guide, and so the number of the progenitors of the theory may be reckoned at from eight to ten.

But what, it may well be asked, are these progenitors or prototypes? for these words are but generic terms, which convey no notion of size, form, or quality. We must, in fact, consider them as atoms or monads of unappreciable minuteness-not visible even by the solar microscope; in truth, nothing better than 'such stuff as dreams are made of.'

'The theory supposes that from the hypothetic progenitors in question-the origin of which it is as impossible for the human mind to conceive as the origin of the universe itself-have descended all living things, from the smallest infusorial animalcule up to the elephant, the whale, and man himself. These mighty results are to be attained through the preservation of 'favoured races in the struggle for life;' that is, by a perpetual sequence of profitable variations in every species of plants and animals. 'The profitable variations, however, which the mutations produce, are so slow, so minute, and so unappreciable that the hypothesis demands millions of years for their accomplishment; an assumption which, as it is unsupported by any fact, places it at once beyond the reach of human investigation, relegating it to the realm of imagination.

Authentic history certainly affords no evidence in favour of the theory of beneficial mutation by natural selection. The wild and even the domestic animals of Egypt have undergone no change in times of an antiquity which has been variously estimated at from 5,000 up to 10,000 years. In the Egyptian catacombs have been found mummies of the ibis and the kestrel hawk, not differing in a feather, or the spot of a feather, from these birds of Egypt of the present day. The ox, the 
ass, the dog, and the goose represented on the Egyptian monuments of equal antiquity, are the same varieties which exist now. If, then, thousands of years have produced no change at all, it is reasonable to believe that, except in dreams, millions would be equally inoperative.

If the living beings of the present earth afford no evidence in support of the theory of transmutation by natural selection, neither do those which lie buried in the earth's crust; and this is, indeed, fully admitted by the ingenious author" of the theory himself. 'Why,' says he, 'does not every collection of fossil remains afford plain evidence of the gradation and mutation of the forms of life?' and he adds, with a candour' which is natural to him, 'we meet with no such evidence, and this is the most obvious of the many objections which may be urged against my theory.' The answer to the objection is, that ' the geological record is imperfect.' The imperfection, however, seems to amount to no more than that the record affords no evidence whatever in favour of the theory of mutation by natural selection, while it is perfect enough in an opposite direction, showing that the lowest forms of life came first into existence, and were followed by a successive series of improvements, ending with man.

As to 'the struggle for life,' there is no doubt but that, through all living beings, it is the weak that perish and the vigorous that survive. Nature in some cases takes some pains for preserving the integrity of the species, but never for its improvement by mutation. 'Thus, with some gregarious animals, the vigorous males, to the exclusion of the young and feeble, are the fathers of the flock or herd. At the beginning, according to the theory of natural selection, there could have existed no 'struggle for life,' when a few inonads, imperceptible by the microscope, had the whole earth to themselves.

Nature, no doubt, supplies us with wonderful mutations of form and character, but they bear no analogy to those ascribed to the Darwinian theory, which are more extravagant than the metamorphoses of Ovid. The tadpole turned 
into a frog, the caterpillar into a butterfly, and a maggot into a bce, are wonderful mutations, but nothing in comparison with those which suppose eight or ten nameless atoms to have peopled the land and the waters with all their varied forms of life. To bear any resemblance to the transformations of the Darwinian theory, the frog ought at least to be transforined into a crocodile, the butterfly into a dove, and the bee into a falcon or eagle.

The arguments in support of the theory of natural selection are, of course, chiefly derived from the varieties which ccasionally arise in plants and animals; and this part of his suljject Mr. Darwin has elaborated with the great skill and ingenuity of a most accomplished naturalist, who has travelled far and studied long. The objections which here present themselves are obvious. Variation in the wild or natural state of plants and animals is rare and evanescent, and can in no case, as far as I know, be shown to result in improvement, or what $\mathrm{Mr}$. Darwin calls ' profitable variation.' It is only in the cultivated state of plants and the domestieated state of animals that variation is frequent; that is, after plants and animals have been long subjected to the control and direction of man. Even then it is but a small number of both that undergoes variation at all. The variety which takes plnce, therefore, under man's direction ought not to be taken into account at all, because, if the theory be true, variation must have been rife for millions of years before man existed, the geological record, the true history of these countless ages, affording no evidence of it.

But, even in plants and animals which undergo variety under man's control, there is a vast difference in the degree in which they do so, even when we are tolerably sure that the wild sourees are the same species. Thus, the variety which the blue rock pigeon and the Indian jungle fowl undergo is endless, while the ass, the two camels, hardly vary at all. Even when variety takes place it ought, as $\mathrm{Mr}$. Darwin expresses it, to be a profitable one to the individual; that is, be such 
an improvement as shall enable it to survive its cotemporarics in the 'struggle for life.' But it turns out to be the very reverse of this. Plants and animals may gain in those qualities which make them most useful or agreeable to man, but they lose those properties which enable them best to maintain the struggle for life. Our poultry lose, for the most. part, the power of flight. The domestic ass, when well cared for, increases in size, but no longer possesses the fleetness of the ass of the desert. The jungle forl of India is a small bird, but vigilant, shy, and powerful of wing; while the domestic bird is large, heavy, and dull, and, if turned into the woods of its native country, would unquestionably perish from incapacity of feeding and defending itself.

Mr. Darwin has given special attention to the breeding of the blue rock pigeon, the only species of its numerous family which is amenable to domestication, and which sports into varieties. These varieties seem to be indefinite in their amount, for besides the more usual sorts, distinguished chiefly by colour, we have such varieties as tumblers, runts, fantails, barbs, pouters, and carriers. Not one of these can be said to have any superior advantage over the wild blue pigeon in so far as regards capacity to maintain the struggle for life, and some of them are of such defective formation that they would surely perish were man's care withdrawn. Moreover, the varieties produced by domestication are not permanently profitable to the individual, as the progressive theory would have us to understand; for it has been ascertained that when the common house pigeon joins the wild birds its peculiarities are, in a short time, absorbed in the mass of the primitive stock; whereas, had the variation been advantageous, it ought, according to the theory, to have been heritable, displacing the wild bird.

It is the same with cultivated plants as with domesticated animals; they gain in size and acquire properties useful or agreeable to man, but they lose in capacity to maintain the struggle for existence. Some of them, such as the cultivated 
rose, the banana and the pine-apple, lose the power of propagation by seed, that is, become virtually sterile, and but for man's care would perish. Domesticated animals and cultivated plants are, in short, but feeble competitors with their wild congeners, and ought not to be quoted as profitable mutations, to say nothing of the non-existence of such varieties for the millions of years which preceded man's first appearance, and during which the theory, were it true, must have been in full operation.

One might have expected that the theory of development by natural selection would, instead of four or five progenitors for animals, and the same, or even a less number for plants, have amounted to a number at least equal to that of their respective natural orders. This would at least have dispensed with the necessity which now exists of imagining such violent and seemingly miraculous transitions as, for example, the growth, in due time, of a mushroom into an oak, or of a sponge into a whale.

The theory makes no provision for disparities of climate, or for the geographical distribution of plants and animals as they now exist, frequently independent of climate. On the contrary, it supposes every plant and animal of land and water to have sprung from eight or ten invisible and indescribable progenitors, which in this case must be imagined to achieve distant migrations; which we know to be impossible to their most fully developed descendants-even to man himself until within the last few generations.

The theory of natural selection by profitable variation of species of course supposes indefinite improvement. For the present, the transmigrations have had their climax in man; but if the theory were true, it ought, after the lapse of a period of time equal in length with that which has transpired since a monad became a man, to produce a being twice as highly gifted as the existing race of mortals. The theory, however, is supposed to terminate in absolute perfection; but why, if the principle of development be well founded, it should ever end at all, is not explained. What, then, does absolute perfection 
consist in? 'To form any conception of it is beyond human understanding, and even the imagination can but form a dim and vague notion of it. The Buddhist doctrine of the metempsychosis cuts the matter short by supposing supreme happiness to consist in absorption into the essence of the Deity, after a long series of transmigrations beginning with a worm, and rising to the dignity of a white elephant and a king - a solution which is probably as intelligible as Dr. Johnson's definition, which makes perfection an attribute of the Deity; which is but getting rid of an insuperable difficulty by taking refuge in the imagination. Even the Buddhist euthanasia would provide only for the highest members of the scale, leaving the rest of living creation to pursue the struggle for life until the turn of all came, when the earth would, of course, be without inhabitants.

A great geologist and naturalist, Sir Charles Lyell, fancies that he sees in the origin and development of languages a corroboration of the Darwinian theory.* The hypothesis on which this view is founded is of recent German origin, and supposes languages, like the prototypes of the theory-the development of species by natural selection-to have been originally few in number, and that from these fer have come the multitude of tongues now found to exist, and which have existed in every authentic period of history. The very reverse of this hypothesis is the fact, and it is not in the nature of things that it should be otherwise. The framing of a language is an operation as factitious as the fashioning of a club, the kindling of fire, or the conversion of a stone into a cutting instrument. When man first appeared he was as destitute of articulate speech as he was of these objects, the mere works of his hands and brain; and he had to compose a language, at first rude and scanty, corresponding with the paucity of his ideas, as he had to fabricate rude tools and weapons.

Languages, instead of being fer in number, must have been

* "The Geological Evidences of the Antiquity of Man, with Remarks on the Origin of Species.' By Sir Charles Lyell, Bart., F.R.S. 
10 THE ORIGIN OF SPECIES BY NATURAL SELECTION.

originally numerous; and for this obvious reason, that man at his first appearance, in his then ignorance and helplessness, must have been thinly scattered over the face of the earth; and this in small tribes or communities, so as to enable them to obtain food. In that early stage men must have been ignorant of each other's very existence, or, if one tribe knew another, its knowledge would extend only to its nearest neighbour, and then only in the quality of an enemy, contending with it in a genuine struggle for life, that is, for a bare subsistence. Each isolated tribe had to frame its own language, and hence a multiplieity of independent tongues was inevitable. Accordingly, in proportion as we approach to the rude primitive state of society, to which I am now referring, independent languages are found to be numerous, while they become fewer in proportion as we recede from it.

The illustration, then, which the origin and listory of language is supposed to give the Darwinian theory, is simply a mistake, and is not a whit more to the purpose than would be the origin of the use of flints for cutting instruments, or of clay for vessels.

In further support of the Darwinian theory, it has been taken for granted that no language - at least no European language -has contimued a living tongue beyond one thousand years; the object in this case being to show that languages, like organic species, are subject to transformation. I am satisfied that the alleged fact is groundless. A language expresses the ideas of the social condition of the people who speak it; and if that condition be stationary, the language must continue a living tongue, not for one thousand years, but for ever. Thus the languages of the Australians had reached the highest mark which those of a people could possibly have attained whose land yielded no plant for cultivation, no animals for domestication-who held no intercourse with strangers from whom they could have derived benefit-and who, moreover, were anong the lowest types of mankind. A people in such a condition being doomed savages, their languages would ne- 
cessarily represent the ideas of savages only; and they may have been in the condition they were in, when first observed by civilised man, not for a thousand but for thousands of years.

It is not necessary, however, that a people should be savages labouring under insuperable privations, in order that language should be nearly stationary and of long endurance. The Arabs of the age of Mahomed were barbarians, but not savages. They were already in possession of a copious, and therefore an ancient language, and the Koran is still considered good Arabic, although written twelve centuries ago. Modern Greek is known to differ from the Greek of the Homeric poems only in the loss of a few inflections; so that the duration of Greek may be reckoned at some threefold the length of time theoretically allotted for duration of a living language.

It is conquest by strangers alone that, by substituting their own tongue for a native one, puts an end to a living language. It by no means always does so even then. It has not done so in certain parts of Britain, Ireland, France, and Spain; and there can be no good reason for not concluding that the native languages now spoken in Ireland, in Wales, in Brittany and in Galicia, may not have been the languages of the time of the Roman conquests, or, indeed, that they may not even then have been ancient languages - the primitive tongues of the inevitable savages who first constructed them. The support, then, which the theory of development receives from the history of language, we may safely conclude, is purely illusory.

There is one argument against the theory of natural development by variation which seems to me to be fatal to it. This consists in the existence of the parasites of plants and animals. These are of inferior organisation to the beings on which and through which they live. They must, therefore, have been either cotemporaneous or posterior creations to the bodies to which they must owe their existence, and as such, either equal or superior developments, instead of being always inferior ones. Why is the misletoe or the fungus of inferior organisation to the trees to which they owe their 


\section{THE ORIGIN OF SPECIES BY NATURAL SELECTION.}

lives? Being either cotemporary creations or more recent developments, they ought to have been more perfect organisations. If man was the last and most perfect emanation of the Darwinian theory, the parasites which trouble him, which are never seen without him, and which are ever most numerous as we approach to the time of his first appearance, being coeval with or of later creation than himself, ought to be his superiors. The theory of progressive mutation by natural selection in the struggle for life could surely not have been in action when organisations of the highest and lowest quality came into existence, at best, at one and the same time.

I come now to consider that branch of my subject which more directly connects the Darwinian theory with ethnology, that which makes the races of Man to proceed from the family of Apes. In bodily form, at least, there is a seeming approximation, but on examination it will soon be seen that the discrepancy is far more striking than the similitude. The most highly endowed ape, in fact, far less resembles man than a hog does an elephant, or a badger a bear. The disparities are, indeed, unspeakable in their extent. In all essential respects, apes are quadrupeds, and nothing better. Nature furnishes them spontaneously with food and clothing, and they continue their race in the same way as all other terrestrial mammals. A monkey can walk on his hind legs, but his pace is shambling; it costs him an effort to walk, and he has to balance himself to preserve his equilibrium. He stands on his hind legs more easily than a dog, but not better than a bear, and his more natural movement is on all-fours like that of any ordinary quadruped, and his most natural is climbing.

All the species of apes are exclusively frugivorous, but all the races of man are omnivorous. The abode of man is the stable earth, but of apes the forest. Were there no trees there would be no apes, and, in fact, in treeless regions they have no existence. Man, of one race or another, is the denizen 
THE ORIGIN OF SPECIES BY NATURAL SELECTION. 13

of every climate; spread, with trifling exceptions, over every part of the firm earth. The family of apes, on the contrary, is restricted to tropical and subtropical regions, provided they be wooded. Yet not even in all such are they found, for there are extensive well-wooded tropical regions wholly destitute of them. Thus they do not exist in the Molucea Islands, in the great island of New Guinea, in any of the many islands of the North and South Pacific Ocean, or in the tropical part of the continent of Australia. Man, then, is the denizen of the whole habitable earth, and apes, his imagined progenitors, only of a small and peculiar portion of it. It should follow from this distribution of the two parties that apes could not have been the progenitors of men unless apes possessed the power of overcoming geographical obstacles insurmountable by man himself while a savage or a barbarian.

Apes vary in size from the magnitude of a marmot to that of a wild boar, but no such disparity exists in the races of man. The greater number of apes have long tails, and the American monkeys prehensile tails, but in all the races of man the termination of the spine is concealed in flesh. The monkeys of Africa, Asia, and the Asiatic Islands have the same number of teeth with man, but the monkeys of America have four additional ones.

Throughout all the various races of man the union of the sexes is followed by a fertile hybrid offspring, but between the different species of apes no union of the sexes takes place at all, even where the species seem most closely allied; so that in this respect they differ more from man than several species of the other lower animals, such as all dogs and some oxen.

The brain of the apes has been deemed by anatomists to make a nearer approach in form and structure to that of man than the brain of any other animal. But the intellectual fruits are not commensurate with this physical resemblance. The ape is brisk, but fitful, artful, and prone to mischief. In sober sagacity he is inferior to the $\log$ and to the elephant; 
14 THE ORIGIN OF SPECIES BY NATURAL SELECTION.

indeed, even to the hog. Monkeys may be tamed, but cannot, even in countries of which they are denizens, be domesticated; so that in this respect they rank, not only below all our domestic cattle, but even below our ordinary poultry. In this last regard, it may be added, that they bear no likeness to man, who even as a savage is a domesticated creature.

The apes are incapable of storing knowledge, and, like ordinary brutes, are one and the same from generation to generation. Is there not in the brain of man and of the lower animals sornething too subtle for anatomy ever to reach? No one alleges that there is any difference in the material properties of the brain of the sagacious and faithful dog and that of the gluttonous and untameable wolf, or in that of the cunning and untameable fox. Anatomy detects no difference in the brains of the docile horse, the wilful ass, or of the zebra incapable of domestication. The brain of a man is not by anatomy distinguishable from that of a woman, although the intellect of man be usually superior to that of woman, while many women far excel the generality of men. No anatomist, I presume, would assert that the brain of Newton could be distinguished by its form or structure from that of an illiterate peasant, or eren from the brain of a savage that could count no higher than the fingers of one of his own hands.

The theory of development by profitable variation makes the family of apes the nearest approach to the variation which ends in man: but it is silent about the gradations in the apes themselves; and there are above a hundred distinct species of them, not one of which is common to $\Lambda$ frica, America, Asia, and the Asiatic islands.

The nearest approach to man, however, is asserted to be found in what are called the anthropoid or man-like monkeys; chiefly, it may be presumed, because like man they have no tails, for it would be difficult to discover any better reason. The anthropoid apes are four in number, and in the order of precedence given to them they are as follows: the gibbon, the chimpanzee, the orang-utan, and the gorilla. But eren 
these are not man-like in the order here set down; for the two first, which in external form bear the least resemblance to man, are by far the most intelligent, while the two last, which make the nearest approach to him, are by far the stupidest; the gorilla, which stands nearest to man, being surpassed in intelligence by many a little monkey with a tail a yard long.

The chimpanzee and gorilla are African apes, so that Africa had two progenitors, a clever and a stupid one. The gibbon is an ape of continental Asia, so that throughout the whole of that great continent, and for its manifold races of man, there was but one progenitor. The Asiatic islands had two - the gibbon and the orang-utan; or rather three, for it is ascertained that there are two distinct species of the latter. America has no anthropoid monkey at all, so that, to people America and its islands with human beings, the gibbon of India, or the orang-utan of Borneo, had to cross the Atlantic - a feat which their savage and barbarous descendants, after attaining the human form by natural selection, were never able to achieve. 'The people of Europe, who had no monkeys in their own country, must trace their simian pedigree to the nearest country; and thus Greeks, Romans, Germans, Frenchmen, and Englishmen would have the same immediate progenitor's as Egyptians, Berbers, Negroes, Abyssinians, and Hottentots, and they have to choose between a chimpanzee and a gorilla. Australia, like Europe, had no ape at all; but as its native inhabitants are among the lowest types of mankind, it ought surely to have had an inferior anthropoid to itself, to show how near a man might be to a monkey.

A skilful anatomist and eloquent teacher, embracing the theory of gradual mutation, has published a work to show the connexion which he considers to exist between man and the ape.* In this work pictured figures of the skeletons of man and the four anthropoid apes are given, in which the

* 'The Evidences as to Man's Place in Nature.' By Thomas Henry Huxley, F.R.S., 1863. 


\section{THE ORIGIN OF SPECIES BY NATURAL SELECTION.}

apes as well as the man are represented as standing erect. It would have been more consonant with nature if the apes had been represented as going on all-fours, and, better still, had they been shown in the act of climbing a tree, or hanging from one of its branches. While Professor Huxley, as a supporter of the Darwinian theory, considers the anthropoid apes-the gorilla at the head of them-as the nearest approach to man, he fully admits that a wide gulf separates them; and, with the candour of a genuine philosopher, he thus expresses limself on the subject: 'Let me take this opportunity of directly asserting that the differences are great and significant - that every bone of the gorilla bear's marks by which it may be distinguished from the corresponding bones of a man, and that in the present creation, at any rate, no intermediate link bridges over the gap between man and the troglodytes.' 'No one,' he adds, 'is more convinced than I am of the vastness of the gulf between civilised man and the brutes, or is more certain that, whether from them or not, he is assuredly not of them.'

But let us for a moment indulge in the belief that the Darwinian theory has, through the creation of a being or beings superior to apes, but inferior to man, bridged over the chasm which now separates them, and that the masterpicee of organic existence is at length reached; still man is but a generic term, for he is divided into many races, or, speaking more correctly, into many species, greatly differing among themselves in bodily and mental attributes. It was incumbent, therefore, on the theory to show that such differences were brought about by ' natural selection in the struggle for' life,' and to indicate with which of the many races the mutation began; or, in other words, which of the races it is that stands nearest to the apes. It makes no attempt of the kind; it simply makes a man out of a monkey and of something else as yet unknown, leaving mankind an indiscrimimate hodge-podge; and so, therefore, the Darwinian theory, except in so far as it protrokes enquiry, is of no value to ethology or the natural history of man. 



